Article

\title{
The New Beamline LISA at ESRF: Performances and Perspectives for Earth and Environmental Sciences
}

\author{
Alessandro Puri *, Giovanni Orazio Lepore and Francesco d'Acapito \\ CNR-IOM-OGG c/o ESRF-The European Synchrotron, LISA CRG, 71 Avenue des Martyrs, CS 40220, \\ Grenoble F-38043, France; lepore@esrf.fr (G.O.L.); dacapito@esrf.fr (F.d.) \\ * Correspondence: puri@esrf.fr
}

Received: 29 November 2018; Accepted: 12 January 2019; Published: 15 January 2019

\begin{abstract}
LISA (Linea Italiana per la Spettroscopia di Assorbimento di raggi X) is the new Italian Collaborating Research Group (CRG) beamline at the European Synchrotron Radiation Facility (ESRF) dedicated to X-ray absorption spectroscopy (XAS). The beamline covers a wide energy range, $4<E<90 \mathrm{keV}$, which offers the possibility for probe the $\mathrm{K}$ and L edges of elements that are heavier than $\mathrm{Ca}$. A liquid $\mathrm{He} / \mathrm{N}_{2}$ cryostat and a compact furnace are available for measurements in a wide temperature range (10-1000 K), allowing for in situ chemical treatments and measurements under a controlled atmosphere. The sub-millimetric beam size, the high photon flux provided, and the X-ray fluorescence detectors available (HP-Ge, SDD) allow for the study of liquid and highly diluted samples. Trace elements in geological or environmental samples can be analyzed, even for very small sample areas, gaining information on oxidation states and host phases.
\end{abstract}

Keywords: XAS spectroscopy; synchrotron radiation; environment

\section{Introduction}

LISA (Linea Italiana per la Spettroscopia di Assorbimento di raggi X) [1,2], the new Italian beamline at the European Synchrotron Radiation Facility (ESRF), is the result of the refurbishment of the former GILDA (General purpose Italian beam Line for Diffraction and Absorption) [3], and it has been open to users since April 2018. The beamline has been designed and optimized for X-ray absorption spectroscopy (XAS).

All the optics were completely renewed, and are fully compatible with the single bending magnet source of the future EBS ring. The X-ray optics consist of two mirrors and one monochromator. The first cylindrical mirror (positioned before the monochromator) collimates the beam in the vertical plane. The double crystal monochromator (DCM) allows the access of a wide energy range (4-90 keV), which offers the possibility to probe the K- and L- edges of most of the elements heavier than calcium (Ca). The DCM contains two crystal pairs: Si(311) for experiments needing high energy resolution, and $\mathrm{Si}(111)$ for experiments needing high photon flux. The second mirror (toroidal, placed after the DCM) focalizes the beam about $17 \mathrm{~m}$ downstream on a roughly circular spot of diameter $\leq 200 \mu \mathrm{m}$. Both mirrors are made of a single crystal Si substrate with two optical regions: one exposing the silicon, and the other coated with Pt. The mirrors operate at a working angle of 2 mrads, with resulting energy cut-off of about 15 and $40 \mathrm{keV}$ for the Si and Pt stripes, respectively. In order to reach energies above $40 \mathrm{keV}$ the mirrors are moved out of the beam. In addition, a pair of Pt-coated flat mirrors working at 8 mrads (cutoff $\approx 12 \mathrm{keV}$ ), located after the second mirror, can be used for harmonics rejection at low energies $(4-6 \mathrm{keV})$. The small spot size and the beam stability during energy scans [2] (beam movement $<10 \%$ of the beam size over an angular range of $30^{\circ}$ for both crystals pairs) allow for the study of samples of reduced dimensions, like small crystals and fibers, or to obtain elemental mappings of the sample with a spatial resolution of down to $\sim 100 \times 65 \mu \mathrm{m}^{2}$. 
The new optics design provides a photon flux of $10^{11} \mathrm{ph} / \mathrm{s}$ on the sample with the $\mathrm{Si}(111)$ crystal pair; this, together with the fluorescence detectors available, a 13-elements ORTEC IGLET-ARRAY-UPGRADE-S and a 12-elements ORTEC C-TRAIN-1200-S High Purity-Ge (HP-Ge), plus a 4-channel Silicon Drift Detector (SDD) ARDESIA [4], allows for the analysis of trace elements in geological or environmental samples, and the study of highly diluted and liquid samples. The detection limit depends on the type of sample (powder, thin film, liquid...) and on the matrix absorption. The estimated value is $10 \mathrm{ppm}$ in atoms, and $1 / 10$ of a monolayer for films.

After the optimization of the beamline optical configuration, the resulting energy resolution, evaluated from the rocking curves Full Width at Half Maximum (FWHM) of the two crystal sets measured in a wide energy range (5-40 keV), is $\Delta E / E=10^{-4}-10^{-5}$ [2], depending on the crystal pair, which is in excellent agreement with theoretical calculations [5].

These features open the possibility of addressing many environmental issues, such as investigating trace elements cycles in the environment, the chemical activities of environmental pollutants, elements speciation, and the characterization of natural/anthropogenic complex matrixes that are not suitable for standard chemical and structural analyses, despite being of crucial importance in environmental sciences.

In this paper, we report on some recent research performed at LISA, pointing out the new beamline possibilities and the work done at the beamline over the last few years in the environmental sciences.

\section{LISA Experimental Hutches}

LISA has two experimental hutches, the principal one (EH2), approximately centered on the focal position of the second mirror, while the other (EH1) is a few meters upstream.

The principal experimental hutch EH2 (Figure 1) is dedicated to experiments needing a focused beam, mainly Extended X-ray Absorption Fine Structure (EXAFS) in fluorescence mode, Grazing Incidence X-ray Absorption Spectroscopy (GIXAS), reflectivity EXAFS (REFLEXAFS), or experiments with diluted or small samples. The experimental apparatuses (vacuum chambers, ion chambers, detectors) are installed on the new $\mathrm{EH} 2$ bench, and can be shifted along the beam path, via sliding plates, in order to accommodate additional instrumentation, and to adapt to the user's needs.

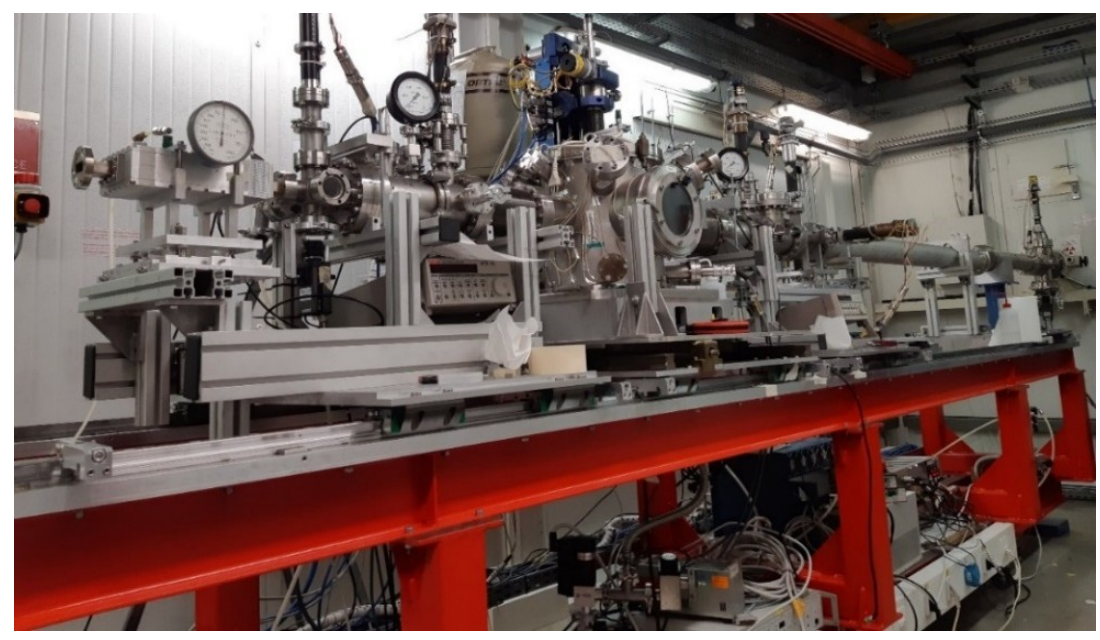

Figure 1. The LISA (Linea Italiana per la Spettroscopia di Assorbimento di raggi X) new experimental hutch, EH2.

Figure 1 shows a typical setup: the main vacuum chamber is equipped with a liquid $\mathrm{He} / \mathrm{N}_{2}$ cold finger cryostat $(10-300 \mathrm{~K})$ and it is preceded and followed by the ion chambers $\mathrm{I} 0$ and I1, respectively. Samples are aligned with motorized vertical and horizontal translations, plus motorized rotations along the vertical axis. Downstream of I1, a small vacuum chamber and a further ion chamber I2 are used to collect reference compound spectra. The fluorescence detectors are mounted on the machine 
wall side of the bench, and can be approached or moved away from the sample with a motorized translation. EH1 is equipped with a vacuum chamber and two ionization chambers. This hutch is dedicated to measurements in transmission mode with an mm-sized beam (typically $2 \times 2 \mathrm{~mm}^{2}$ ), as it is far from the focal point of the second mirror. Furthermore, the beamline is equipped with a compact furnace for measurements at high temperature (up to $1000 \mathrm{~K}$ ), under a controlled atmosphere, and is thus suitable for in-situ chemical treatments.

Energy scans are performed in step mode. Users can adjust the energy mesh for each region of the XAS spectrum. The dead time is $1.5 \mathrm{~s}$ per point in transmission mode, and slightly higher in fluorescence mode, due to the detector readout. We would like to stress the fact that the main goal of the beamline is to obtain high-quality low-noise measurements with very good energy stability.

\section{XAS Spectra of a Single Riebeckite Fiber}

As an example of the performances of the new LISA beamline, in Figure 2, we report the Fe K-edge XAS spectra of a single $500 \mu \mathrm{m}$ sized fiber of synthetic riebeckite $\left(\mathrm{Na}_{2} \mathrm{Fe}^{2+}{ }_{3} \mathrm{Fe}^{3+}{ }_{2}\left(\mathrm{Si}_{8} \mathrm{O}_{22}\right)(\mathrm{OH})_{2}\right)$. The fibrous forms of riebeckite are known as crocidolite, and are one of the six types of asbestos. They represent a serious issue for health, due to their carcinogen effects, which are thought to be involved in malignant mesothelioma and lung cancer. However, the mechanism by which asbestos and other mineral fibers cause cancer is still poorly understood. The iron contained in the fiber is suspected to play a prominent role in the process.

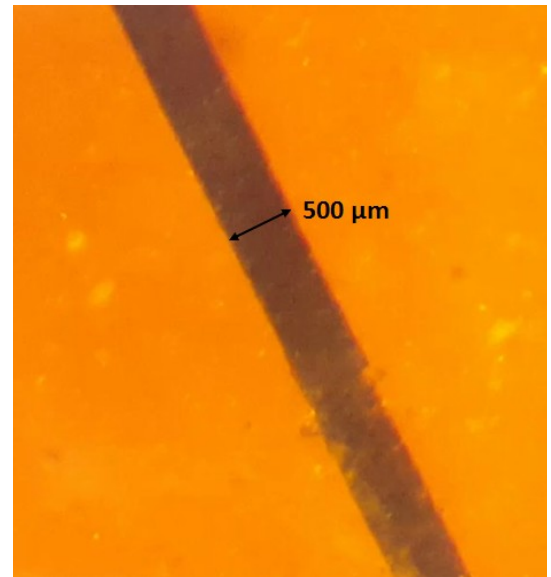

(a)

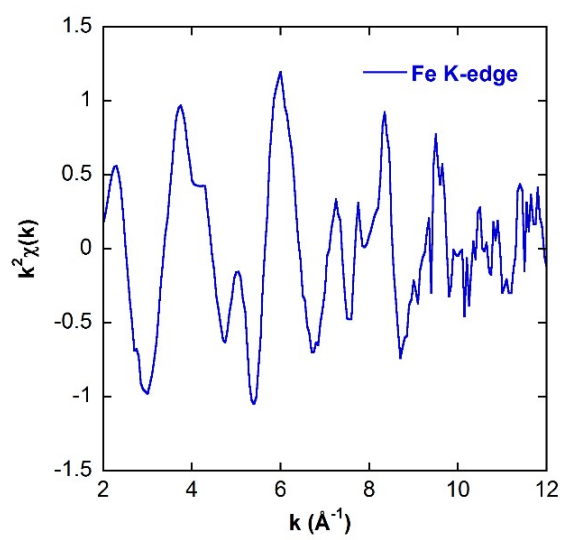

(c)

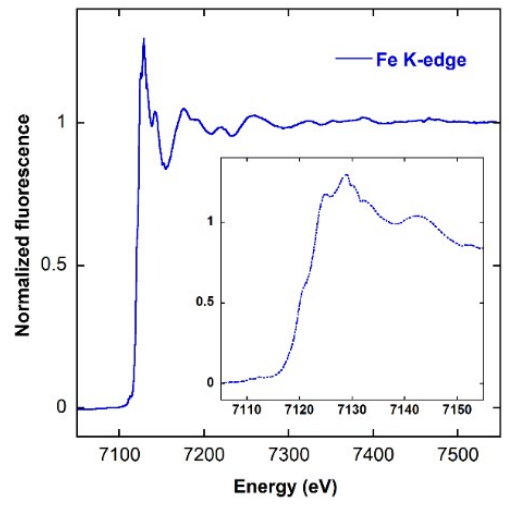

(b)

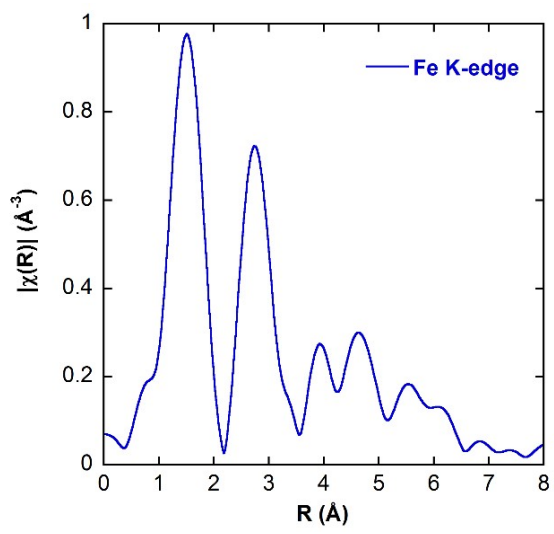

(d)

Figure 2. (a) Photograph of the riebeckite fiber embedded in kapton; (b) Fe K-edge Extended X-ray Absorption Fine Structure (EXAFS) of the fiber, the inset shows the X-ray Absorption Near-Edge Structure (XANES) region; (c) $\mathrm{k}^{2}$-weighted EXAFS spectrum; (d) $\mathrm{k}^{2}$-weighted EXAFS Fourier Transform magnitude. 
The spectra have been collected in fluorescence mode using the ORTEC 12-elements HP-Ge detector mounted behind the measurement chamber (Figure 1), and the $\mathrm{Si}(311)$ crystal pair. The beam was focalized in a $200 \mu \mathrm{m}$ spot and the fiber, rotated $45^{\circ}$ with respect to the incoming X-ray beam, was oriented with the long axis, i.e., the $c$-axis, parallel to the radiation polarization plane, allowing a single fiber embedded in kapton to be probed. A time period of 90 min were necessary to acquire a complete spectrum, with $10 \mathrm{~s}$ counting time per point.

A good signal-to-noise ratio was obtained up to $10 \AA^{-1}$ in $\mathrm{k}$, allowing for the resolution of several coordination shells around the Fe atom. The EXAFS data analysis is in progress to better clarify the structural environment of iron.

In Figure 3, we compare the pre-edge of the single fiber with that of a powdered sample of riebeckite. In the fit, we used Gaussian curves for each component, left free to vary the energy position in a range of $\pm 0.75 \mathrm{eV}$ from the initial value. Their FWHM was constrained to be constant at $\sim 1.5 \mathrm{eV}$ (the core-hole of Fe). The incoming energy resolution was $\sim 0.3 \mathrm{eV}[6,7]$.

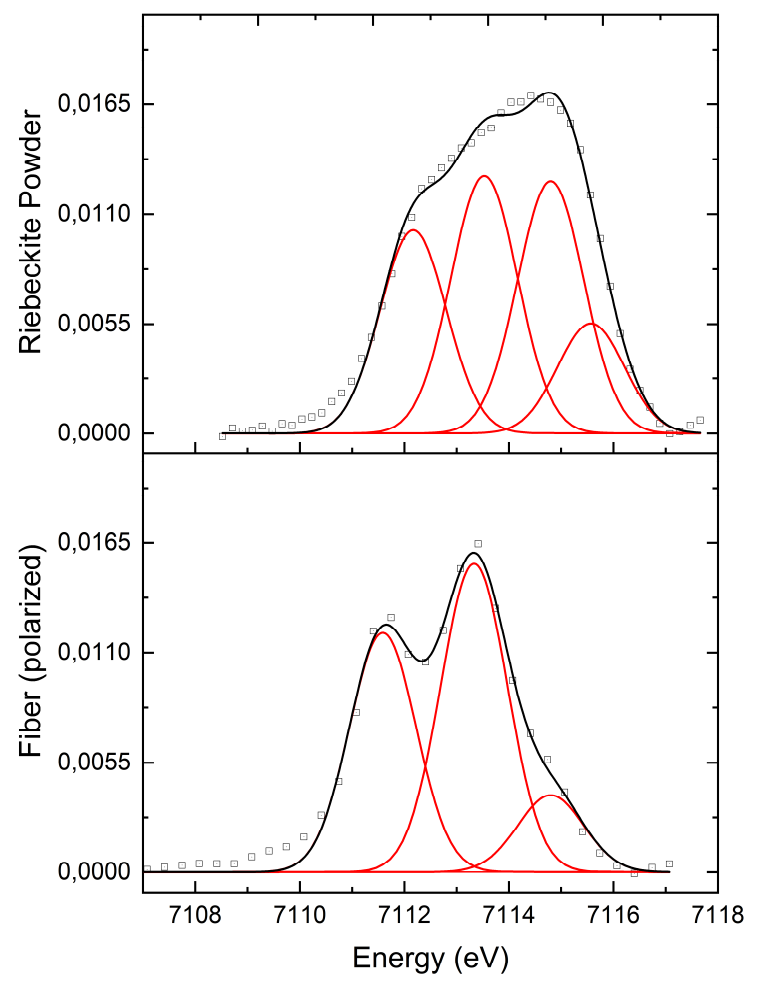

Figure 3. Comparison between the pre-edge of a powdered sample of riebeckite (top) and that of a $500 \mu \mathrm{m}$ thick fiber of riebeckite (bottom).

The spectra show clear differences: for the single fiber oriented parallel to the beam polarization the pre-edge is sharper, and two features are easily visible, while it is broader for the powder sample, where four contributions are needed in the fit, probably due to the multi-orientation of the grains. This evidences the importance of having a small polarized beam in these kinds of experiments.

\section{Chemical Activities of Environmental Pollutants in Aerosols Stored in Snow and Ice-Cores from Western China and the Arctic Atmosphere}

A long-term project on the investigation of snow and ice samples retrieved from glaciers located around the Tibetan plateau and Antarctica is currently being carried out at LISA, to shed light on the role played by iron in climatic and environmental systems, in particular regarding their relationship with atmospheric dust and the aerosol cycle.

Snow and ice deposited on the glaciers represent an invaluable archive of climatic and environmental information, in particular, with respect to the atmosphere. The Tibetan region and its 
glaciers are surrounded by the most populated and industrialized areas. On the other hand, Antarctica, due to its remoteness with respect to human activities, can be considered as a global background, which is extremely useful for assessing the trends and mechanisms that are modifying the global biogeochemical cycles of many elements.

A selection of Fe K-edge XANES and EXAFS spectra of soil samples is presented in Figure 4; the spectra have been collected in fluorescence mode by using the same geometrical configuration described in Section 3. A SDD single channel detector Vortex EM from the ESRF instrument pool and the $\mathrm{Si}(111)$ crystal pair were used. Each spectra was acquired in $50 \mathrm{~min}$ ( $5 \mathrm{~s}$ counting time per point), and in some cases for the most diluted samples several spectra were averaged for the final spectrum. In this way, although the statistic was not exactly the same, the noise resulted to be sufficiently low to allow a reliable data analysis. The origin, type, and average Fe concentration of the samples are indicated in Table 1.

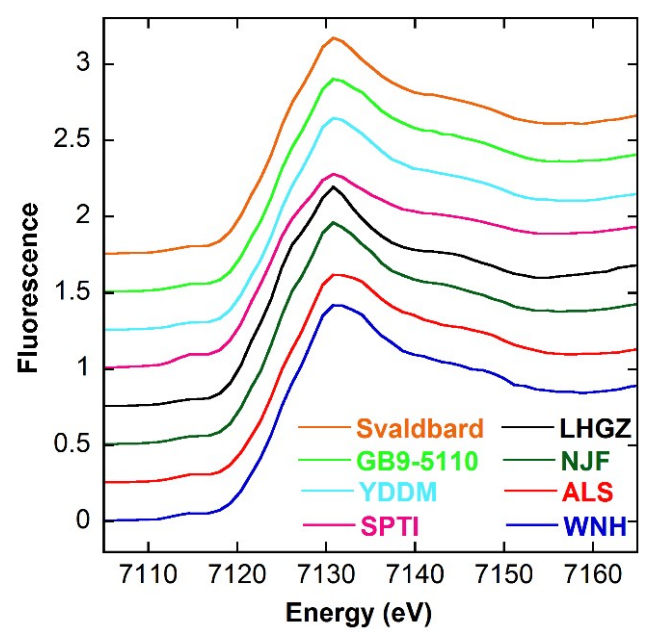

(a)

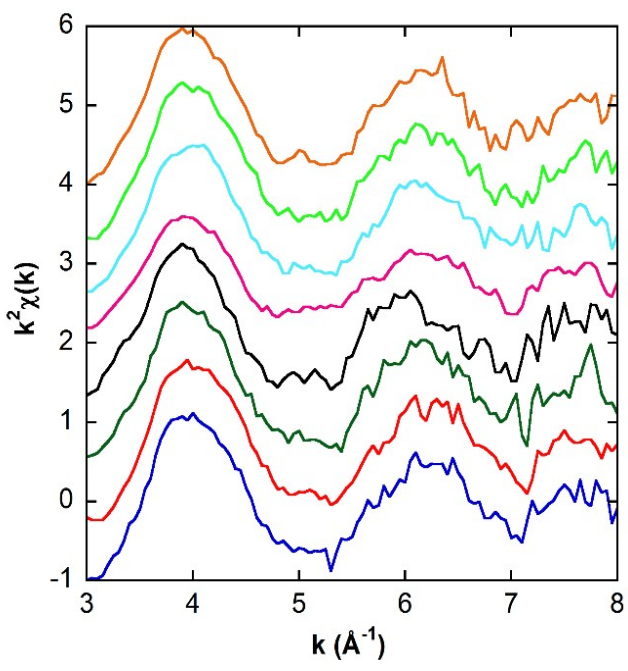

(b)

Figure 4. Comparison of several spectra at the Fe K-edge from different samples: (a) XANES region; (b) $\mathrm{k}^{2}$-weighted EXAFS signal. The curves are shifted vertically for clarity.

Table 1. Origins of samples presented in Figure 3.

\begin{tabular}{cccc}
\hline Name & Type & Average Fe Concentration $(\mathbf{m g} / \mathbf{k g})$ & Location \\
\hline Svalbard & sand & $1.99 \times 10^{4}[8]$ & Svalbard \\
GB9-5110 & sand & $2.50 \times 10^{3}$ & Inner Mongolia \\
YDDM & sand & $2.50 \times 10^{3}$ & Near Dunhuang City \\
SPTI & sand & $2.50 \times 10^{3}$ & Near Tengger desert \\
LHGZ & sand & $2.50 \times 10^{3}$ & Laohugou glacier No. 12 station \\
NJF & sand & $2.50 \times 10^{3}$ & (Western Qilian Mountain) \\
ALS & loess & $1.03 \times 10^{1}$ & Zhongshan Station (Antarctica) \\
WNH & loess & $1.03 \times 10^{1}$ & Wulatehouqi (inner Mongolia) \\
\hline
\end{tabular}

The spectra show marked differences: sample SPTI shows a more intense pre-edge peak at $7115 \mathrm{eV}$, a broad hump at $7126 \mathrm{eV}$, and a less pronounced white line at $7131 \mathrm{eV}$; sample LHGZ shows two more pronounced features at $7122 \mathrm{eV}$ and $7126 \mathrm{eV}$, and a sharper white line at $7131 \mathrm{eV}$, which on the contrary, is broader for the ALS and WNH samples; these last two samples show a broad hump at $7125 \mathrm{eV}$. These differences point out the variability in Fe oxidation, coordination, and mineralogy in samples of different types and provenances. 


\section{Recent Research in Environmental Science}

LISA and the former GILDA have allowed for a broad range of Earth and environmental issues to be addressed recently. Besides the long-term project on the study of snow and ice samples from the Tibetan plateau and Antarctica regions discussed above, a similar study of iron speciation in Arctic snow and soil samples from the Spitzbergen region (Svalbard) is under investigation. A great deal of effort is being devoted to the study of contaminants in the environment, especially regarding the particulate air pollution, along with the distribution of heavy metals or toxic elements in water, soil, plants, and to the speciation and reaction pathways of metals and other environmentally relevant elements in minerals and rocks.

Among the published works based on measurements performed at the beamline in the last few years, we point out the investigation of $\mathrm{Tl}$ contamination of the drinkable water from the public distribution system of Valdicastello Carducci-Pietrasanta (northern Tuscany, Italy) [9]; the study of As contamination of floodplain soils and groundwater from shallow aquifers [10,11]; the study of Fe chemical environment in asbestos and erionite mineral fibers [12]; the investigation of selenium (Se) and lead $(\mathrm{Pb})$ accumulation, distribution, and speciation in edible plants $[13,14]$; the Fe speciation in urban particulate matter and industrial quartz dusts $[15,16]$; the investigation of amorphous zinc (Zn) biomineralization ("white mud"), occurring at Naracauli stream, Sardinia [17]; the Sb speciation in brake linings, brake pad wear residues, road dust, and atmospheric particulate matter [18]; the interaction of As-rich natural pyrite with aqueous selenite [Se (IV)] [19], and As speciation in travertines [20].

\section{Conclusions}

The new Italian CRG beamline LISA has completed its construction, and it has been open to users since April 2018. The high photon flux ( $10^{11} \mathrm{ph} / \mathrm{s}$ on the sample with $\mathrm{Si}(111)$ crystal pair), the reduced beam size (less than $200 \mu \mathrm{m}$ beam spot), and the possibility to work in fluorescence mode, provide a valuable tool for earth and environmental scientists. Highly diluted samples and trace elements in host matrices can now be analyzed with unprecedented accuracy and precision compared to the previous GILDA beamline.

For more information and the latest news about the beamline, please visit the LISA webpage: http:/ / www.esrf.eu/UsersAndScience/Experiments /CRG/BM08.

Author Contributions: Conceptualization, G.O.L.; Data curation, A.P.; Supervision, F.d.; Writing—original draft, A.P.; Writing-review \& editing, G.O.L. and F.d.

Funding: This research received no external funding.

Acknowledgments: We acknowledge Giancarlo Della Ventura (Roma Tre University) for the fiber sample presented in Section 2, Federico Galdenzi (Roma Tre University) for Figure 3 and the fit presented in Section 2. We acknowledge Augusto Marcelli (INFN-Laboratori Nazionali di Frascati), Giannantonio Cibin (Diamond Light Source), Giovanni Baccolo (Università degli Studi di Milano-Bicocca), Valter Maggi (Università degli Studi di Milano-Bicocca), and Du Zhiheng (Chinese Academy of Sciences), for the data presented in Section 3.

Conflicts of Interest: The authors declare no conflict of interest.

\section{References}

1. d'Acapito, F.; Trapananti, A.; Puri, A. LISA: The Italian CRG beamline for X-ray Absorption Spectroscopy at ESRF. J. Phys. Conf. Ser. 2016, 712, 012021. [CrossRef]

2. d'Acapito, F.; Lepore, G.O.; Puri, A.; Laloni, A.; La Mannna, F.; Dettona, E.; De Luisa, A.; Martin, A. The LISA beamline at ESRF. J. Synchrotron Radiat. 2019, in press.

3. d'Acapito, F.; Trapananti, A.; Torrengo, S.; Mobilio, S. X-ray Absorption Spectroscopy: The Italian beamline GILDA of the ESRF. Notiziario Neutroni e Luce di Sincrotrone 2014, 19, 14-23.

4. Bellotti, G.; Butt, A.D.; Carminati, M.; Fiorini, C.; Bombelli, L.; Borghi, G.; Piemonte, C.; Zorzi, N.; Balerna, A. ARDESIA Detection Module: A Four-Channel Array of SDDs for Mcps X-Ray Spectroscopy in Synchrotron Radiation Applications. IEEE Trans. Nucl. Sci. 2018, 65, 1355-1364. [CrossRef] 
5. Ishikawa, T.; Tamasaku, K.; Yabashi, M. High-resolution X-ray monochromators. Nucl. Instrum. Methods Phys. Res. A 2005, 547, 42-49. [CrossRef]

6. Galdenzi, F.; Della Ventura, G.; Cibin, G.; Macis, S.; Marcelli, A. Accurate Fe3+/Fetot ratio from XAS spectra at the Fe K-edge. Radiat. Phys. Chem. 2018, in press. [CrossRef]

7. Della Ventura, G.; Galdenzi, F.; Cibin, G.; Oberti, R.; Xu, W.; Macis, S.; Marcelli, A. Iron oxidation dynamics vs. temperature of synthetic potassic-ferro-richterite: A XANES investigation. Phys. Chem. Chem. Phys. 2018, 20, 21764-21771. [CrossRef] [PubMed]

8. Zhan, J.; Gao, Y.; Li, W.; Chen, L.; Lin, H.; Lin, Q. Effects of ship emissions on summertime aerosols at Ny-Alesund in the Arctic. Atmos. Pollut. Res. 2014, 5, 500-510. [CrossRef]

9. Biagioni, C.; D'Orazio, M.; Lepore, G.O.; d'Acapito, F.; Vezzoni, S. Thallium-rich rust scales in drinkable water distribution systems: A case study from northern Tuscany, Italy. Sci. Total Environ. 2017, 587-588, 491-501. [CrossRef] [PubMed]

10. Parsons, C.T.; Couture, R.-M.; Omoregie, E.O.; Bardelli, F.; Greneche, J.-M.; Roman-Ross, G.; Charlet, L. The impact of oscillating redox conditions: Arsenic immobilisation in contaminated calcareous floodplain soils. Environ. Pollut. 2013, 178, 254-263. [CrossRef] [PubMed]

11. Phan, V.T.H.; Bonnet, T.; Garambois, S.; Tisserand, D.; Bardelli, F.; Bernier-Latmani, R.; Charlet, L. Arsenic in Shallow Aquifers Linked to the Electrical Ground Conductivity: The Mekong Delta Source Example. Geosci. Res. 2017, 2, 180-195.

12. Pollastri, S.; D’Acapito, F.; Trapananti, A.; Colantoni, I.; Andreozzi, G.B.; Gualtieri, A.F. The chemical environment of iron in mineral fibres. A combined X-ray absorption and Mössbauer spectroscopic study. J. Hazard. Mater. 2015, 298, 282-293. [CrossRef] [PubMed]

13. Eiche, E.; Bardelli, F.; Nothstein, A.K.; Charlet, L.; Göttlicher, J.; Steininger, R.; Dhillon, K.S.; Sadana, U.S. Selenium distribution and speciation in plant parts of wheat (Triticum aestivum) and Indian mustard (Brassica juncea) from a seleniferous area of Punjab, India. Sci. Total. Environ. 2015, 505, 952-961. [CrossRef] [PubMed]

14. Massaccesi, L.; Meneghini, C.; Comaschi, T.; D’Amato, R.; Onofri, A.; Businelli, D. Ligands involved in Pb immobilization and transport in lettuce, radish, tomato and Italian ryegrass. J. Plant Nutr. Soil Sci. 2014, 177, 766-774. [CrossRef]

15. d'Acapito, F.; Mazziotti Tagliani, S.; Di Benedetto, F.; Gianfagna, A. Local order and valence state of Fe in urban suspended particulate matter. Atmos. Environ. 2014, 99, 582-586. [CrossRef]

16. Di Benedetto, F.; D’Acapito, F.; Capacci, F.; Fornaciai, G.; Innocenti, M.; Montegrossi, G.; Oberhauser, W.; Pardi, L.A.; Romanelli, M. Variability of the health effects of crystalline silica: Fe speciation in industrial quartz reagents and suspended dusts-Insights from XAS spectroscopy. Phys. Chem. Miner. 2014, 41, 215-225. [CrossRef]

17. Medas, D.; Lattanzi, P.; Podda, F.; Meneghini, C.; Trapananti, A.; Sprocati, A.; Casu, M.A.; Musu, E.; De Giudici, G. The amorphous Zn biomineralization at Naracauli stream, Sardinia: Electron microscopy and X-ray absorption spectroscopy. Environ. Sci. Pollut. Res. Int. 2014, 21, 6775-6782. [CrossRef] [PubMed]

18. Varrica, D.; Bardelli, F.; Dongarrà, G.; Tamburo, E. Speciation of Sb in airborne particulate matter, vehicle brake linings, and brake pad wear residues. Atmos. Environ. 2013, 64, 18-24. [CrossRef]

19. Kang, M.; Bardelli, F.; Charlet, L.; Géhin, A.; Shchukarev, A.; Chen, F.; Morel, M.-C.; Ma, B.; Liu, C. Redox reaction of aqueous selenite with As-rich pyrite from Jiguanshan ore mine (China): Reaction products and pathway. Appl. Geochem. 2014, 47, 130-140. [CrossRef]

20. Winkel, L.H.E.; Casentini, B.; Bardelli, F.; Voegelin, A.; Nikolaidis, N.P.; Charlet, L. Speciation of arsenic in Greek travertines: Co-precipitation of arsenate with calcite. Geochim. Cosmochim. Acta 2013, 106, 99-110. [CrossRef]

(C) 2019 by the authors. Licensee MDPI, Basel, Switzerland. This article is an open access article distributed under the terms and conditions of the Creative Commons Attribution (CC BY) license (http:/ / creativecommons.org/licenses/by/4.0/). 